\title{
The role of dynamic response parameters in damage prediction
}

\author{
Behzad Ahmed Zai', M. A. Khan², Kamran Khan³ ${ }^{3}$ Asif Mansoor ${ }^{4}$, Majid Shahzad ${ }^{5}$, \\ Aqueel Shah ${ }^{6}$
}

\author{
${ }^{I}$ Department of Engineering Sciences, PN Engineering College, National University of Sciences and Technology (NUST), \\ Karachi,Pakistan, behzad_zai@pnec.nust.edu.pk \\ ${ }^{2}$ School of Aerospace, Transport and Manufacturing, Cranfield University, Cranfield, UK, \\ muhammad.a.khan@cranfield.ac.uk \\ ${ }^{3}$ Aerospace Engineering Dept. Khalifa University, Abu Dhabi, UAE, kamran.khan@ku.ac.ae \\ ${ }^{4}$ Department of Engineering Sciences, PN Engineering College, National University of Sciences and Technology (NUST), \\ Karachi, Pakistan, asifmansure@gmail.com \\ ${ }^{5}$ Advanced Material Research Division, SUPARCO, Pakistan, dr majid@engineer.com \\ ${ }^{6}$ Department of Engineering Sciences, PN Engineering College, National University of Sciences and Technology (NUST), \\ Karachi,Pakistan,aqueel@pnec.nust.edu.pk
}

\begin{abstract}
This article presents a literature review of published methods for damage identification and prediction in mechanical structures. It discusses methods which can identify and predict structural damage from dynamic response parameters such as natural frequencies, mode shapes, and vibration amplitudes. There are many structural applications in which dynamic loads are coupled with thermal loads. Hence, a review on those methods which have discussed structural damage under coupled loads is also presented. The published research is critically analyzed and the role of dynamic response parameters in structural health monitoring is also discussed. The conclusion highlights the research gaps and future research direction.
\end{abstract}

Keywords: Damage quantification, Dynamic response, Thermomechanical loads, Fatigue, Crack propagation, structural health monitoring.

\section{Introduction}

Damage in mechanical structures often investigates from conventional nondestructive testing techniques. These techniques measures local or global behavior of a structure [1-2]. For example, ultrasonic and acoustic emissions measure the local behavior of a structure. However, the constraints, like the prior knowledge of local region of interest and the accessibility in mounting the sensing probe, develop complexities in their use. The latter can be avoided if a non-contact technique is available, such as X-rays, digital image correlation (DIC) and thermography. These non-contact techniques are comparatively difficult in their signals interpretation and more often complex in use due to their raw data post-processing [3].

Researchers measure global structural response for damage prediction and avoid the mentioned difficulties in local response measurement. Structural vibration is used most rigorously for global response analysis and measurements [4]. It can identify specific faults in the system and can also lead the repair of structures or components by diagnosing the root cause of damage. Published methods show that a vibration response can estimate structural or component damage long before their potential catastrophic failure. This early warning of emerging damage helps in scheduling a reliable preventive maintenance at any industry.

Structures demonstrate vibratory or oscillatory (i.e. dynamic) response if an external excitation (i.e. force) interacts with them. The characteristic of this response, such as displacement amplitude, mode shape and frequency, is dependent on stiffness of a structure. Stiffness of a structure is a direct measurement of elastic properties of its material [4]. The elastic properties of a material are determined 
by its microstructure and hence even a very small disturbance or damage in microstructure can eventually affect dynamic response of a system.

The dynamic response of a structure is normally measured with respect to time. The stochastic nature of time domain signals makes damage identification challenging [5]. However, the conversion of these signals into frequency domain caters these challenges and distinctly estimate the response parameters such as natural frequency, mode shape, and vibration amplitude.

In structures or machine components, fatigue failure is very common. It is initiated by a small defect which leads it to a catastrophic failure. The material defects, inclusion, impurities and machine operation can always be vulnerable for crack initiation and hence fatigue mostly cannot be avoided. In metallic structures, the thermal loads can also alter the material properties such as young's modulus, tangent modulus, yield stress, and ultimate tensile strength etc. Consequently, in the presence of increasing temperature, it can be inferred that the material might become soft near the vicinity of the crack tip, which can lead to increase the size of the plastic zone under the same mechanical loads. Therefore, it is very complex to estimate the retardation or acceleration of fatigue crack propagation under thermomechanical loads.

In the last 30 years, researchers have used dynamic response parameters quite rigorously for damage prediction in mechanical structures. This article presents a literature review of published methods for damage identification and prediction in mechanical structures. It discusses methods which can identify and predict structural damage from dynamic response parameters such as natural frequencies, mode shapes, and vibration amplitudes. There are many structural applications in which dynamic loads are coupled with thermal loads. Hence, a review on those methods which have discussed structural damage under coupled loads is also presented. The published research is critically analyzed and the role of dynamic response parameters in structural health monitoring is also discussed. The conclusion highlights the research gaps and future research direction.

\section{Research Based on Dynamic Response Calculations}

\subsection{Damage quantification based on natural frequency}

This section discusses how the researchers have used natural frequency of a structure for damage quantification. Natural frequency of a structure can be measured easily at any location. Nandwana et al. [6-7] used an inverse Eigenvalue problem and detected size and location of a crack in a beam with multiple supports as shown in Figure 1. In this figure, $\mathrm{L}_{1}, \mathrm{~L}_{2}$, and $\mathrm{L}_{3}$ are lengths of the three sections and $\beta$ is the location of the crack. They modeled crack as a rotational spring with a stiffness $K_{t}$ and established a relation between stiffness, natural frequency and crack location. Accuracy of this relation was found dependent on size, depth, and location of crack. They also observed that the change in natural frequency is insignificant if crack is located near to the support ends.

(a)

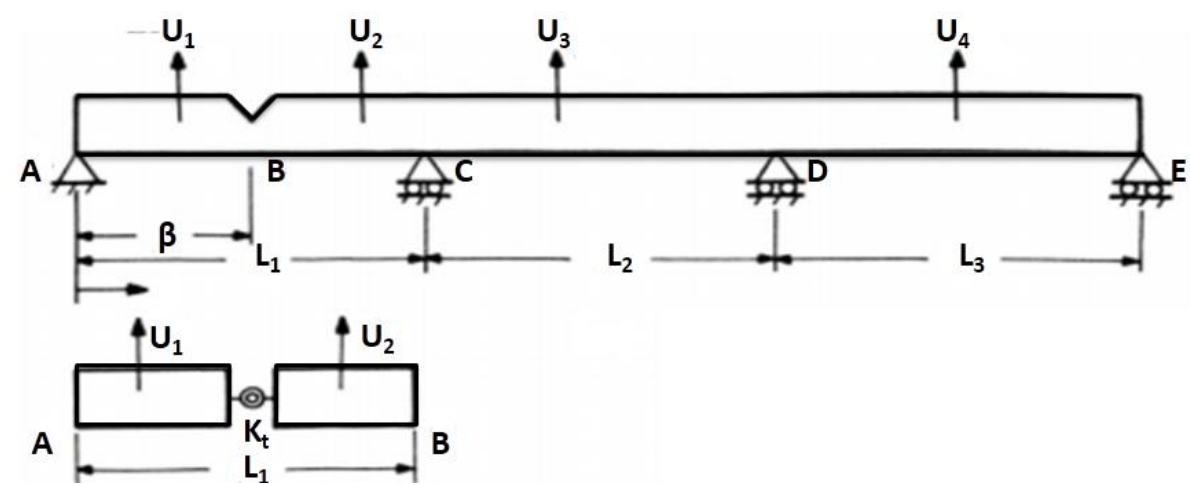

Figure 1: (a) Crack in a beam having multiple supports (b) Representation of crack by rotational spring. 
Khorshidi et al. [8] proposed a natural frequency based method and diagnose vertical or transverse crack in a beam. Same like previous, they modelled crack as a massless rotational spring. They developed a relation between natural frequency and crack depth by using Rayleigh quotient and a few governing equations which were solved by generalized quadrature method as shown in Eq. (1) - Eq. (5).

$$
K_{t}=\frac{E B H^{2}}{72 \pi f(\alpha)}
$$

$f(\alpha)=0.638 \alpha^{2}-1.035 \alpha^{3}+3.720 \alpha^{4}-5.177 \alpha^{5}+7.553 \alpha^{6}-7.332 \alpha^{7}+2.491 \alpha^{8}$

and $\alpha=\frac{t_{c}}{H}$

$$
\begin{aligned}
& E I \frac{\partial^{4} y}{\partial x^{4}}+\rho A \frac{\partial^{2} y}{\partial t^{2}}=0 \\
& \Delta u=\frac{M^{2}}{2 k_{t}} \\
& \Delta \omega_{n c}=\frac{\Delta u}{2 u} \omega_{n} \\
& \omega_{n c}=\omega_{n}-\Delta \omega_{n c}
\end{aligned}
$$

Where $K_{t}$ is stiffness of rotational spring, $E$ is modulus of elasticity, $B$ is width of a beam, $H$ is thickness, $L$ is length of a beam and $f(\alpha)$ is a function depends on crack depth $\left(t_{c}\right)$ and location of crack $(x)$.

Free bending vibration of a uniform beam expressed by Eq. (2), which is a well-known differential equation. The natural frequency of a cracked beam was evaluated by using Eq. (3) - Eq. (5). In these equations, $u$ is strain energy, $M$ is bending moment and $\omega_{n c}$ is natural frequency of a cracked beam.

A few other researchers used the same approach [9-11]. They analyzed the effects of open cracks on natural frequencies of a cantilever beam as shown in Figure 2. In this figure, $\mathrm{L}$ is length of a beam; $\mathrm{L}_{1}$ and $\mathrm{L}_{2}$ are locations of crack. They also measured the effect of crack position and its severity on natural frequency values from analytical functions. For single sided and double sided cracks, they used Eq. (6) and Eq. (7) respectively.

$$
\begin{aligned}
& f(a / H)=1.13-1.374(a / H)+5.749(a / H)^{2}-4.464(a / H)^{3} \\
& f(a / H)=1.003-1.349(a / H)+5.896(a / H)^{2}
\end{aligned}
$$

Where, $H$ is half height of a beam and $a$ is crack depth. The proposed method observed as more effective in the presence of two closed cracks. In case of separated cracks, additional response parameters, such as amplitude and damping were considered for better accuracy in results. 


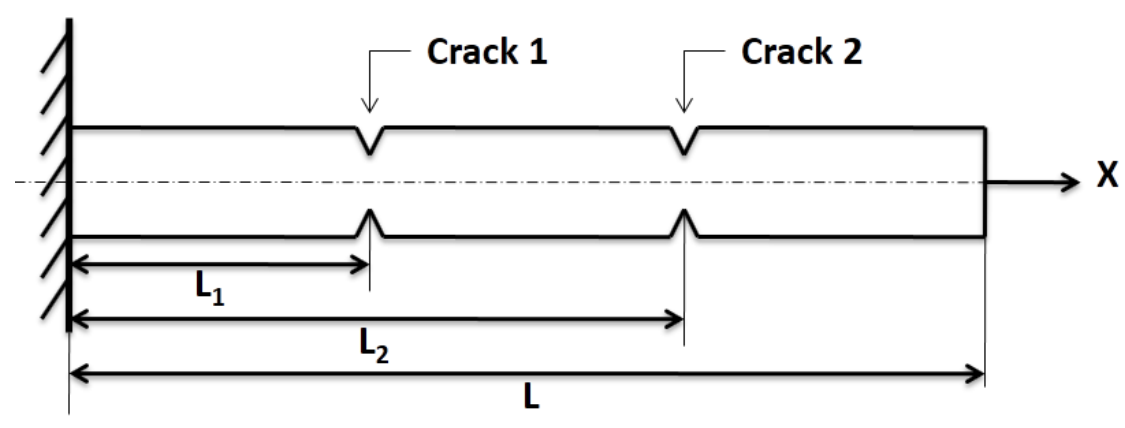

Figure 2: Clamped beam with two cracks.

A significant number of researchers used analytical, numerical and experimental approaches simultaneously. They quantified crack in a beam and used natural frequency as an input [12-24]. They observed the changes in natural frequency if the crack propagates. Changes in natural frequency were found insignificant in case of smaller cracks and hence entailed modification in methods based on natural frequency.

Schlums and Dual [25] experimentally characterized the crack propagation and its effect on natural frequency as expressed in Eq. (8). They also accounted for a factor of non-linearity in crack growth due to the crack closure phenomenon. They developed a model considering non-linearity but for a crack located at the center of a structure.

$$
f_{o 1}\left(\frac{a}{b}\right)=\frac{2}{\frac{f\left(a_{o} / b\right)}{f(a / b)}+1} f\left(\frac{a_{o}}{b}\right)
$$

Where, $a_{o}$ is depth of an initial notch, $f\left(a_{o} / b\right)$ is resonant frequency before a crack is initiated from a starter notch and $f(a / b)$ is frequency from the linear theory of completely reversed loading.

Various others numerical methods were developed for damage quantification but they were based on the variations of natural frequency [26-28]. They assessed crack location and crack size in different beam structures. Gounaris and Dimarogonas [29] developed a finite element model of a cracked prismatic beam. They developed a compliance matrix in the vicinity of a crack and used strain energy concentration as an input. They estimated stiffness with this matrix and used dynamic response values to characterize crack. Orhan [30] studied free and forced vibration of a cracked beam and calculated single and two-edge cracks numerically with finite element analysis (FEA). Thatoi et al. [31] and Ratnam et al. [32] developed an approach for multiple cracked cantilever beams and obtained the changes in natural frequency with experimental validation. These frequency-based approaches are illposed because cracks with different severity in two sets of different locations can produce identical changes at lower frequency modes.

A robust iterative algorithm was proposed for damage growth estimation in the beams by Xu et al. [33]. The algorithm used perturbation and inverse methods and predict damages from the values of lower order natural frequencies. To cover all possible crack locations on a structure, they used a combination of different scenarios. The changes in natural frequencies were also used to determine position and size of transverse cracks in a rotatory machine with the help of a transfer matrix method and the famous Timoshenko beam theory [34-35]. The proposed method used changes of natural frequencies for damage quantification. However, a distinct frequency change was observed difficult to obtain due to double resonance values of the cracks with higher severity (a saw-cut removing 60 percent of the cross-sectional area). The coupling of flexural and axial vibrations caused this double resonance behavior and distributed the stresses in a non-uniform manner. It also limited the application of frequency-based method to a range of crack depths.

Smith and McGowan [36] used a scaled truss model for locating a crack in structures. Their approach was also based on frequency measurement. Cawley and Adams [37] \& Cawley and Ray [38] estimated 
structural integrity from low order natural frequencies measurements. They found that the values of a given crack depth and changes in natural frequency have a direct relation with the width of crack as shown in Figure 3. The reliability of obtained results was limited to specific slot depths. Ruotolo and Surace [39] published a finite element method for crack size quantification. They used frequency of low order as a modal parameter and applied their method on beams as expressed in Eqs. (9-10). Multiple measurement points were used to obtain the desired data for simulations and hence the research was limited to heavy structures only.

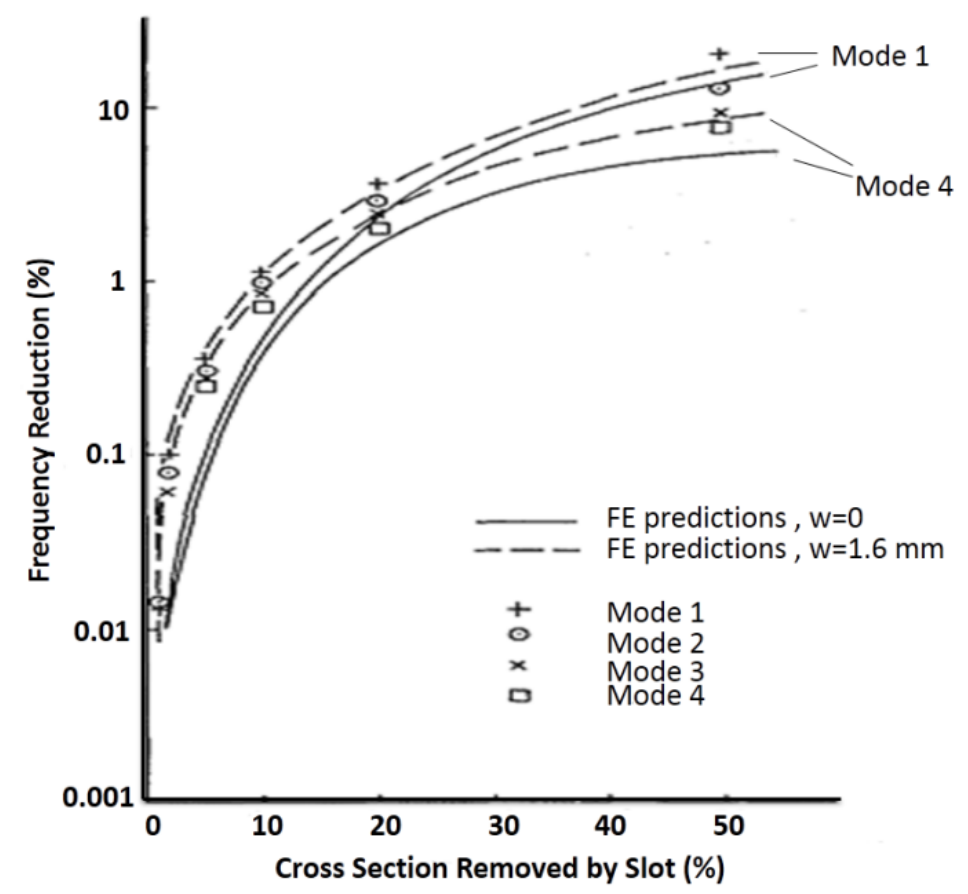

Figure 3: Experimentally measured change in natural frequency due to slots.[Referece]

$$
\begin{aligned}
& g_{1}(\tilde{R})=\sum_{i=1}^{N}\left(1-\frac{f_{i}^{*(m)} / f_{i}^{(m)}}{f_{i}^{*(c)}(\tilde{R}) / f_{i}^{(c)}}\right)^{2} \\
& g_{2}(\tilde{R})=\sum_{i=1}^{N} \sum_{j=1}^{M}\left(\emptyset_{i, j}^{\prime \prime(c)}(\tilde{R})-\emptyset_{i, j}^{\prime \prime *(m)}\right)^{2} \\
& \tilde{R}=\left\lfloor\begin{array}{llll}
r_{1} r_{2} & r_{3} & \ldots & r_{n}
\end{array}\right]^{\mathrm{T}} \\
& r_{1}=\frac{a_{i}}{h}
\end{aligned}
$$

Where, $\widetilde{R}$ is a vector representing a state of damage in structure, $n$ indicates number of elements that make up a structure, $a_{i}$ is depth of notch, $h$ is beam height, and $\mathrm{N}$ is number of natural frequencies, asterisk represents cracked structure, superscript $(c)$ is calculated frequency and superscript $(m)$ is measured frequency. The difference between modal curvatures of simulated and cracked structures was expressed by Eq. (10). $M$ is degree of freedom of a structure and $\emptyset_{i, j}^{\prime \prime *}$ is the $\mathrm{j}^{\text {th }}$ degree of freedom of the $\mathrm{i}^{\text {th }}$ modal curvature.

Lateral vibrations of a cracked Euler Bernoulli beam were also studied for single or double edge cracks identification [40-42]. These studies were based on the vibration theory of continuous systems and 
further used for detection of faults [43]. However, for symmetrical systems, these procedures were unable to produce a unique solution, indicating that the fault may occur at either of the two locations.

Dentsoras and Dimarogonas [44] studied fatigue crack growth in resonating members of a distributed mass as shown in Figure 4. In this figure, ' $a$ ' is crack depth, $\mathrm{W}$ is width, $\mathrm{K}$ is stiffness and $\mathrm{L}$ is length of a beam. They established a relation between local flexibility and crack depth from natural frequency. But the relation was limited for only those cracks which were located near supports with substantial depths. Gudmundson [45-46] presented a first-order perturbation method and predicted change in natural frequency due to a crack in terms of strain energy of a structure as expressed in Eq. (11). This change in natural frequency was also used to devise a nondestructive evaluation procedure for identifying a crack based on a simple reduced stiffness model [47].

(a)

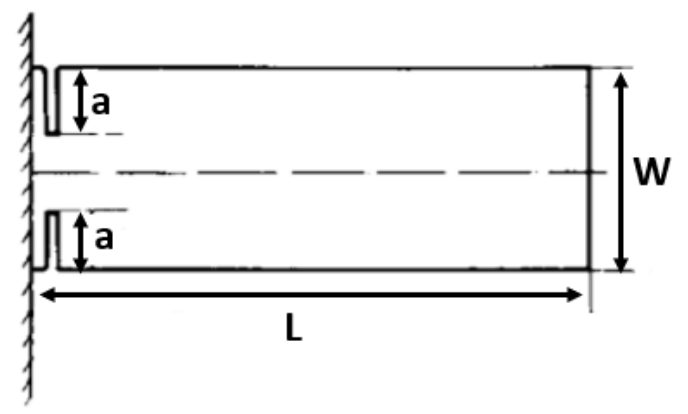

(b)

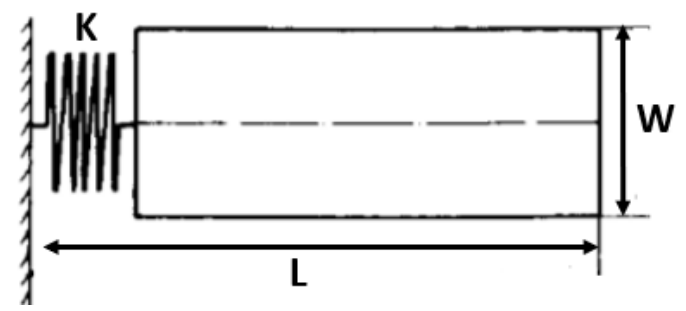

Figure 4: (a) Geometry of a cracked cantilever beam, (b) Equivalent system.

$$
\begin{aligned}
& \omega_{\text {crack }}^{2}=\omega_{n}^{2}\left[\frac{W^{\prime}}{W_{o}}\right] \\
& W^{\prime}=\int_{V^{\prime}} \frac{1}{2} \varepsilon_{i j}^{\prime} \sigma_{i j}^{\prime} \mathrm{d} V \\
& W_{o}=\int_{V} \frac{1}{2} \varepsilon_{i j}^{n} \sigma_{i j}^{n} \mathrm{~d} V
\end{aligned}
$$

Where, $\omega_{\text {crack }}$ is natural frequency of a cracked beam, $\omega_{n}$ is undisturbed natural frequency, $W^{\prime}$ is strain energy for the corrected displacement, $W_{o}$ is total strain energy in the $\mathrm{n}^{\text {th }}$ mode of vibration equal to the total kinetic energy. $V$ is volume, $\varepsilon_{i j}$ is undisturbed strain tensor, $\sigma_{i j}$ is undisturbed stress tensor and $n$ is mode number.

Many researchers assumed crack in a structure as a rotational mass-less spring. However, solution of this assumption required a significant amount of computation [48-52]. A transfer matrix approach was proposed by Khiem and Lien [48] as shown in Figure 5. In this figure, $a_{1}$ to $a_{\mathrm{n}}$ are depths of the cracks, $k_{1}$ to $k_{n}$ are stiffnesses and $x_{1}$ to $x_{\mathrm{n}}$ are crack locations. This approach eliminated the numerical computation of high order determinant and hence addressed the challenge of computation in the calculation of natural frequencies. They concluded that the modeling of crack as a rotational spring (based on fracture mechanics) is not suitable at higher modes or for deep cracks. Therefore, these methods are only applicable to a slender beam-type structure with small cracks. 


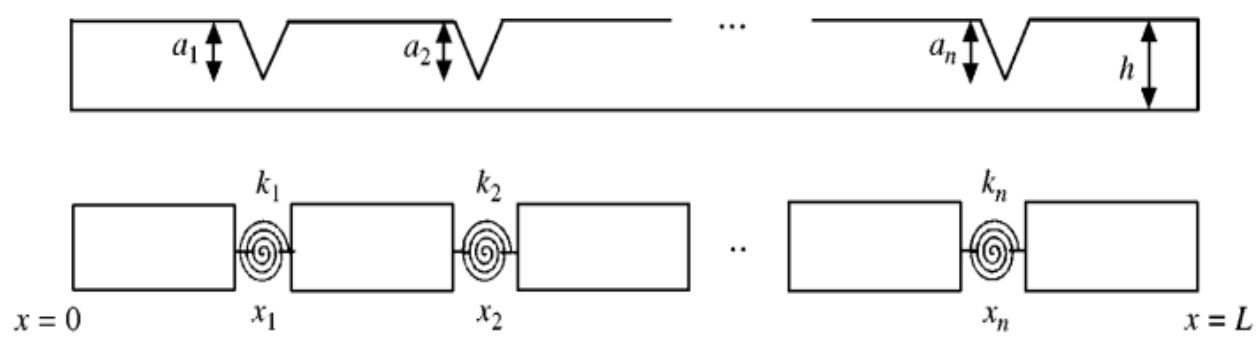

Figure 5: Model of multiple cracked beams.

Krawczuk and Ostachowicz [49] analyzed the influence of one-edge open transverse cracks on natural frequencies of a cantilever beam subjected to vertical loads. They also proposed an algorithm which can be used to calculate the linear and geometrical stiffness of a cracked element, but this algorithm is only applicable for deep cracks.

The response parameter of natural frequency can be measured with ease. Therefore, in the past three decades, many researchers have used this parameter to quantify damage but still the proposed methods have known limitations. One fundamental limitation is modeling of the crack. In the above-mentioned research, cracks were more often modeled in Euler-Bernoulli beam systems and showed a tendency of over prediction in estimating the frequency value (especially in case of short beams at high vibration modes). The assumption of a physical crack in terms of massless rotational spring effects the estimation of natural frequencies at high modes and for deep cracks.

The physical measurement of change in natural frequency can be very challenging especially in the presence of small-scale damages in structures with highly damped boundary conditions. The change of frequency would be buried in such structures without showing a measurable observation.

The non-unique output of frequency-based detection is also a problem in damage estimation. Damage with different severities and at different locations can produce the same change in frequency value. This problem becomes more complex in the presence of multiple cracks. This issue can be resolved by using the changes in high order frequency, but available analytical solutions have shown limitations in high order estimations.

\subsection{Damage quantification based on natural frequency and mode shape}

Natural frequency-based damage identification is limited to simple structures, deep cracks, and specific crack locations. It requires testing in a control laboratory environment. Dynamic response in terms of a structural shape deformation is commonly known as mode shape and it can be used to cater this limitation. Mode shapes are highly sensitive to local damages and hence in the presence of multiple cracks, they can distinctly locate damage even from a global dynamic response.

In past, researchers frequently used mode shapes to get damage locations [53-55]. They observed that the frequency alone cannot be sufficient to locate damage, as similar damage at different locations can produce a similar frequency change. Same estimations were also made on transverse shaped cracks but distinct relations were developed to correlate crack depth with natural frequency and mode shape respectively [56-58]. Two accelerometers were used. One at the fixed end and the other was moved to get mode shape and made it less useful for in-situ measurements.

Numerical analyses were also used to investigate the effects of cracks on mode shapes of a beam as shown in 
Figure 6 [59]. Significant changes in mode shapes were observed with a change in crack depth and its opening size. The mode shapes were obtained with limited sensors hence roughly estimated at higher modes.
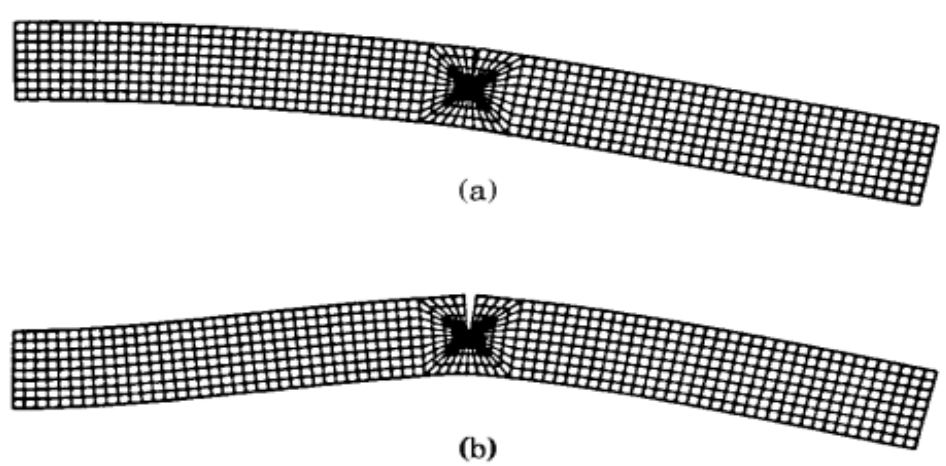

(b)

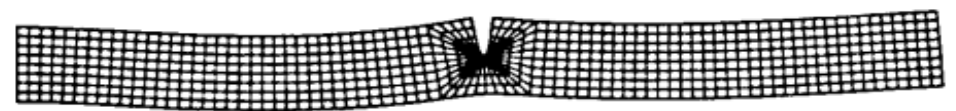

(c)

Figure 6: Unconstrained mode shapes for the (a) first (b) second and (c) third mode.

Pandey et al. [60] developed a relation between changes in Eigen parameters, damage location, and damage size. In their research, curvature mode shape was used for identifying and locating damage in a structure. They detected damage in a structure from absolute changes in curvature mode shape. The measurement of these changes required many sensing points and hence limited their research. To avoid this problem, curvature mode shape can be used in conjunction with natural frequency.

A general beam element with an open double-sided crack was analytically derived and used for modeling damage in complex structures [61-62]. This model estimated changes in natural frequencies and mode shapes for a given depth of damage and its location using a complex stiffness matrix obtained from an intricate analytical computation. The same methodology was also used and model dynamic response parameters in the presence of a non-propagating edge crack [63]. Flexibility of a rotating beam developed a unique mode shape. The location of crack was approximated in transverse and slant directions at various depths.

Crack depth and location in a frame structure were also investigated by using natural frequencies and mode shapes [64-67]. These researchers used multiple sensors and data points. Other researchers [6869] used response parameters and predict crack propagation in a rotatory machine from an axial vibration measurement on a uniform cross-section shaft. Changes were observed in measured vibration response with a shift in crack size and its location for a non-propagating crack.

Shen and Pierre [70] suggested an approximate Galerkin solution for modeling free bending motion of beams in the presence of symmetric and open cracks. A series of functions were used to compare the possible mode shapes with their corresponding uncracked beams. For a general Galerkin solution, the conversion of the solution was very slow, therefore a secondary function was added to improve the conversion rate; this made the solution more complex. Moreover, the presented mode shapes were not affected by smaller cracks. Few more researchers adopted analytical approaches based on bending vibration theory of Euler-Bernoulli beams and predicted damage with multiple cracks [71-73]. The crack 
identification equation of a cracked beam was obtained explicitly by using a nontrivial solution of vibration mode shapes. This equation was further used to relate natural frequencies, locations, and depths of the cracks. Accuracy of the proposed method heavily dependent on size of the structure and crack depth. For such cases, the dynamic response in terms of amplitude can be more accurate.

The incorporation of mode shape with natural frequency provides better results in damage prediction. But it has few limitations. It requires many sensors on a structure to capture the actual change in the physical shapes. Mode shapes are more sensitive to noise as compared to natural frequency. Moreover, the amplitudes of the mode shapes are imaginary due to unknown structural damping and therefore a change in shape can only show evidence of damage in a structure.

\subsection{Damage quantification based on natural frequency and vibration amplitude}

This section presents research efforts for damage detection from vibration amplitudes and natural frequencies measurements. Both of these parameters can be measured from a single probe and hence effective in use as compare the above.

Qian et al. [74] derived an element stiffness matrix of a cracked beam. They applied integration of stress intensity factors (SIFs) on beam finite elements and calculated the respective displacement responses as shown in Figure 7. The amplitudes were derived from the known stress intensity factor.

Papadopoulos and Dimarogonas [75-77] investigated longitudinal and bending vibrations of a rotating shaft with an open transverse surface crack. Local flexibility in a short shaft cracked element was assumed to have six degrees of freedom. A coupling in between longitudinal and bending vibration amplitude was found in the cracked shaft. Coupling behavior and value of sub-critical resonance recognized the crack in the rotating shaft. This proposed methodology showed accurate results for damage identification but quantified crack size inadequately. Later, a systematic framework was proposed to correlate crack location, crack size, changes in natural frequency and amplitude of a cantilever beam [78]. The results showed a significant trend between the dynamic response parameters and the attributes of a crack. The trend was further evaluated from mode shape variation.

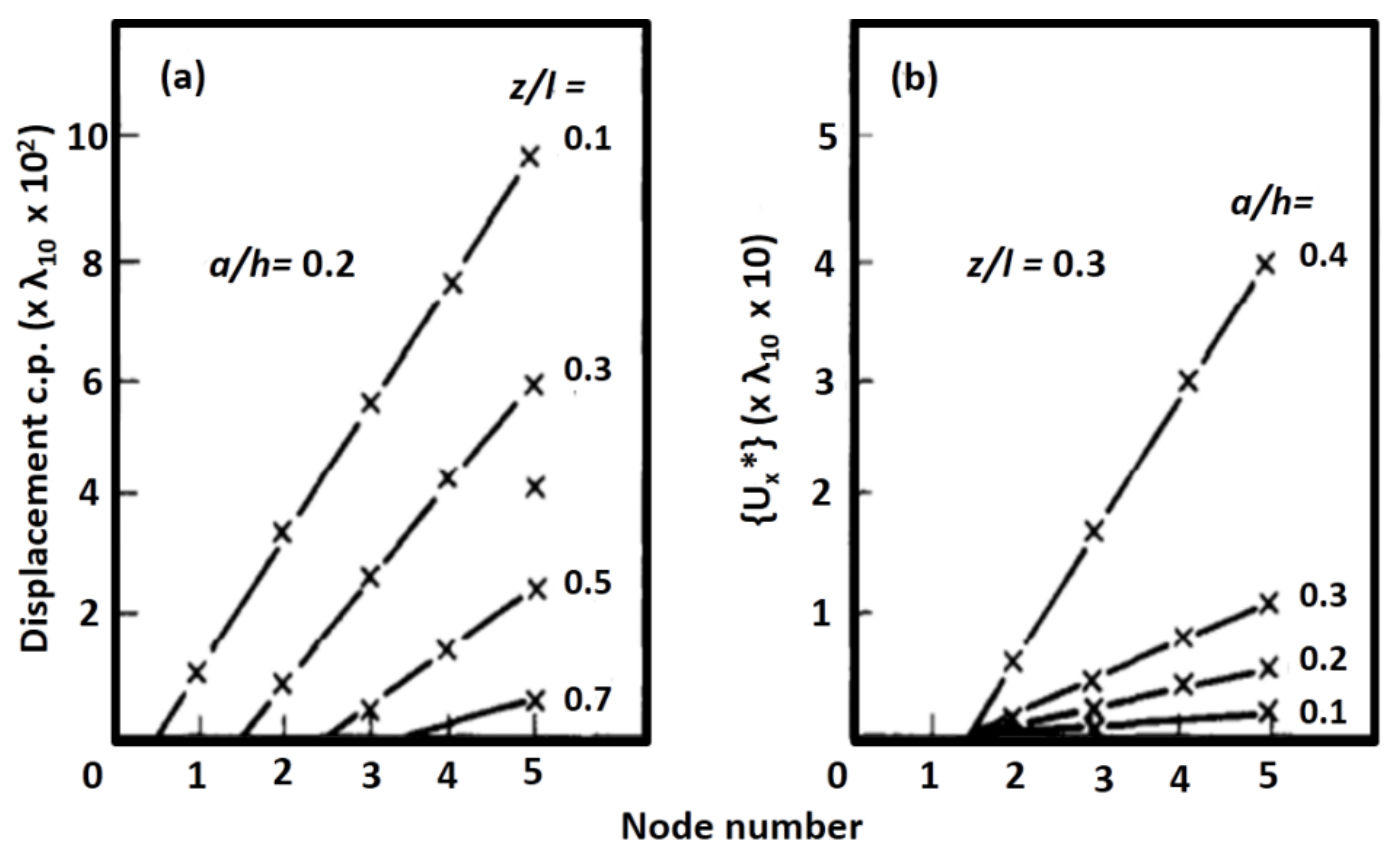

Figure 7: Characteristic parameters for different crack positions and for different crack length. 
Boltezar et al. [79] and Jena et al. [80] worked out a crack identification procedure. They derived it for a free-free uniform beam under flexural load and used vibration amplitudes and mode shapes as the key inputs. Two equal segments on the beam at each side of a crack were considered in calculations. This made the whole method limited and dependent on the location of crack. Gasch [81] presented behavior of a rotating shaft in the presence of a crack. He found a relation between shaft imbalance and damage severity. Mayes and Davies [82] described flexural vibration of a rotor mounted on several bearings with a transverse crack. They developed an analytical compliance function based on modules, crack location and geometric parameters. They also calculated the change in few non-resonating frequencies to confirm the presence of a crack.

\subsection{Research efforts on estimating crack propagation with dynamic response parameters}

Crack behavior in conjunction with its propagation is always a point of interest in many industrial applications. Agama et al. [83] presented a correlation between natural frequencies and crack initiation of a friction stir spot welding (FSSW) in four different welding processes. Similar crack propagation trends were reported when variation of natural frequency in tensile/shear spot-welded joints was observed as shown in Figure 8 [84-87]. Considering the limitations of natural frequency-based damage identification, the frequency reduction was inconsistent compared to fatigue damage.

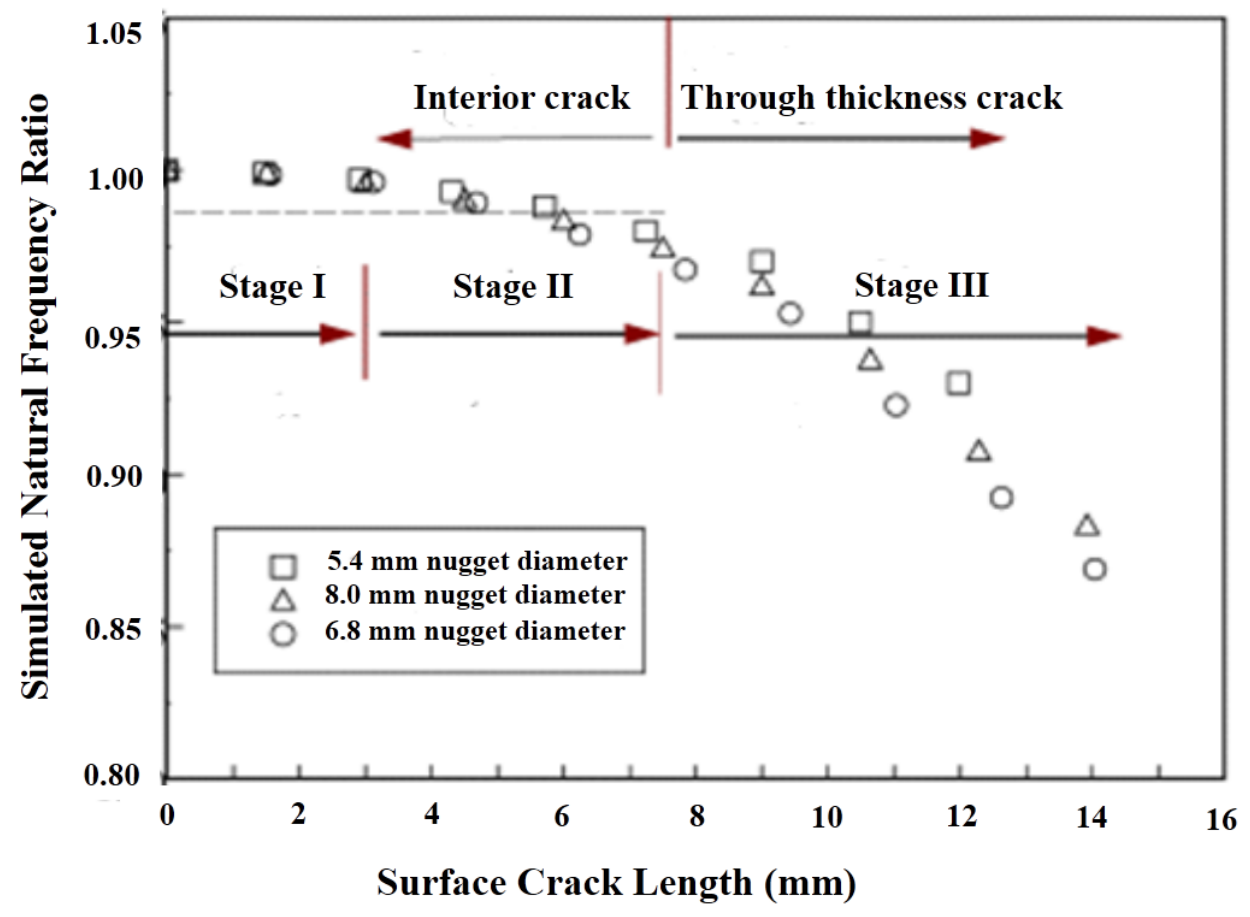

Figure 8: Variation of the threshold stress with crack length.[References]

A concurrent structural prognosis was proposed for bridges [88]. The proposed method was based on a novel small-time scale formulation of material crack growth as shown in Figure 9. Oskouei and Dumanoglu [89] developed an analytical model of propagating crack and investigated the behavior of a concrete dam on different values of crack length. They estimated fatigue life in the presence of a nonpropagating variable crack length. 

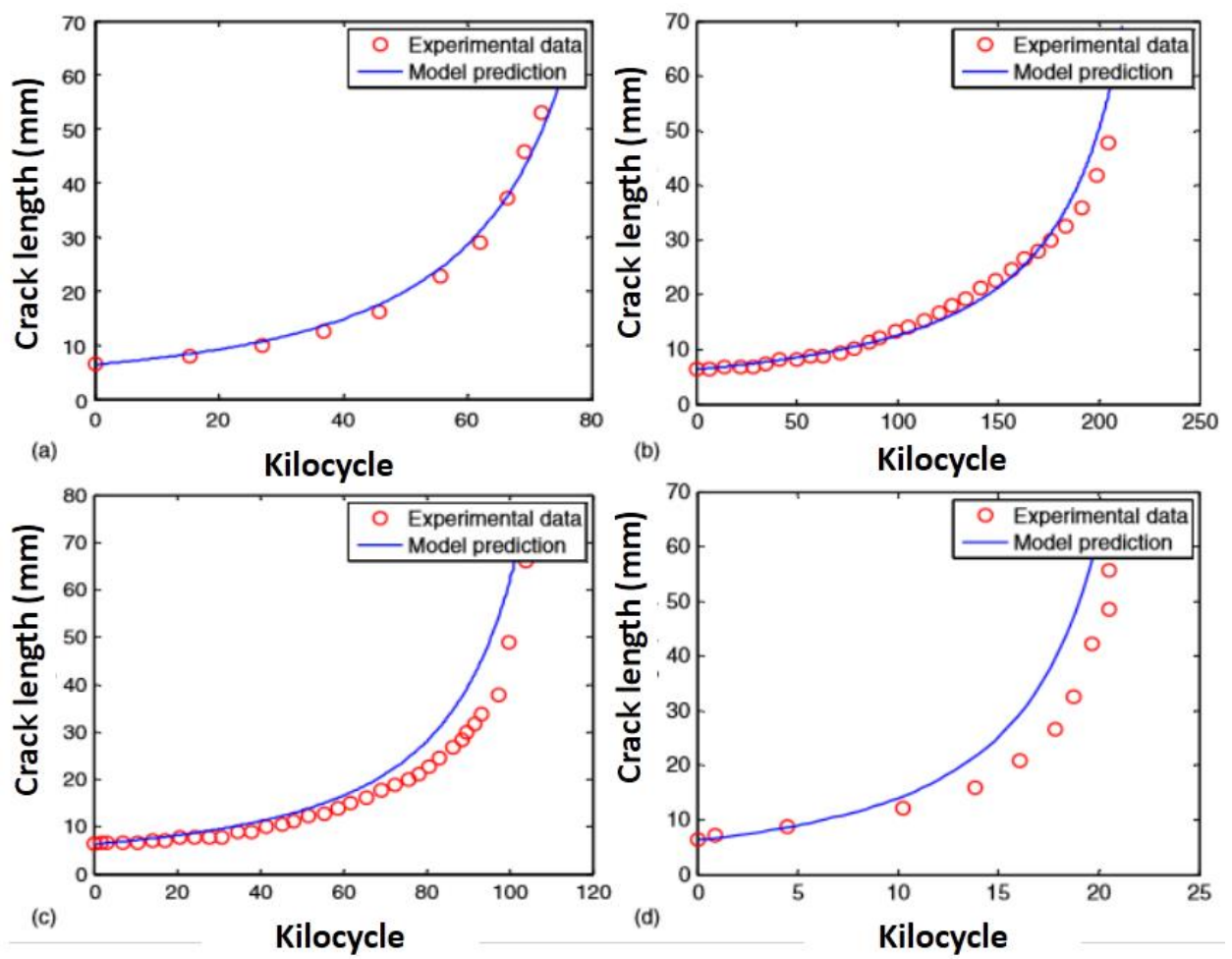

Figure 9: Comparison of crack length between small timescale model prediction and experimental data.

Nwosu et al. [90] presented an analytical study on vibration response of a tubular T-joint. They detected cracks along the intersections of the joints from the variations in the bending moments or the physical mode shapes. Rao and Eischen [91] performed failure analysis on a fractured frame rail of a heavy-duty truck. Metallographic examination revealed micro-cracks on the edges of an open hole located in an area of high-stress concentration causing fatigue crack initiation. The results showed a curvilinear crack growth under dynamic loads of the vehicle as shown in Figure 10. Similar research on fatigue crack growth at normal, resonating and particular frequencies was also reported and showed the effectiveness of the dynamic response parameters [92-95]. These studies were based on stress concentration, thus requiring additional consumable strain gauges at affected areas. Wang et al. [96] described the use of a fracture mechanics-based modeling approach to explain the experimental observations in solder joints subjected to high-speed cyclic bending. They modeled two-dimensional crack fronts based on dynamic response parameters for estimating the fatigue life in a solder joint.

The vibration-based damage quantification is not limited to the simple structure, it is equally applicable to more complex industrial structure such as rotors wind turbine and rotor shaft [97-104]. The presented research emphasized fatigue life estimation. The correlation in between the response parameter with changing crack depth could be added to proposed methodologies. Moreover, many researchers measured the stress concentration for fatigue life estimation which requires installation of consumable strain gauges at affected areas. Thus, it can delay essential preventive maintenance. 


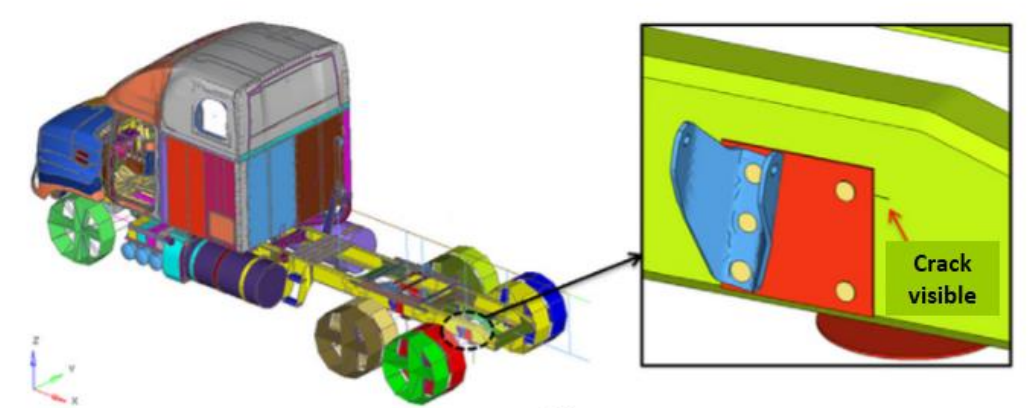

(a)

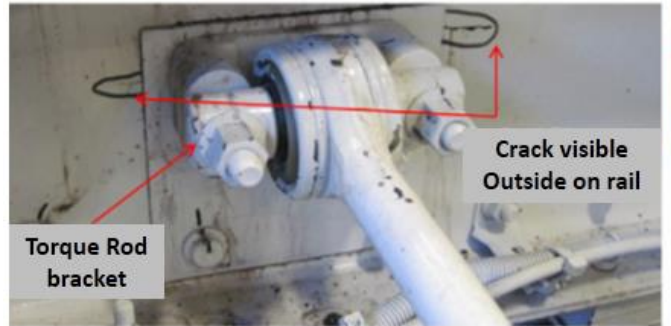

(b)

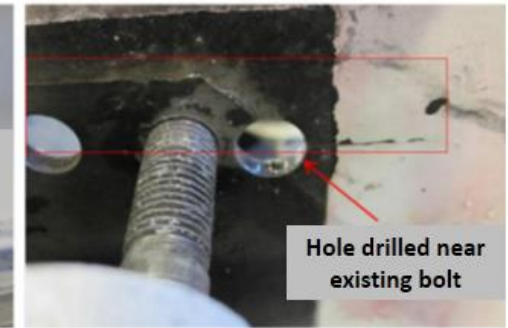

(c)

Figure 10: (a) Full vehicle layout and failure location (b) Frame cracks visible near torque rod connection (c) Crack path visible on frame behind outer reinforcement plate.

\section{$3 \quad$ Structural health monitoring using other approaches}

In this section, various structural health monitoring techniques are discussed. These methods are based on elastic wave propagation, wavelet transform, modal parameters, and other analytical approaches.

Krawczuk et al. [105] presented a method of wave propagation analysis in cracked plates. Elastic behavior of a plate at a crack location replaced with a line spring and observed this behavior along different values of crack length by varying spring stiffness. ZAK et al [106] and Kudela et al. [107] numerically and experimentally observed the propagation of guided elastic waves in thin-walled shell structures and successfully employed the damage maps via integral indices. Similar research was conducted by Kumar et al. [108] on a composite beam with transverse crack.

Surface-breaking cracks in metallic structures were investigated by Lee et al. [109]. They used wave propagation theory and proposed lamb waves for damage detection in metallic structures. They proposed that the numerical simulations can significantly ease the monitoring strategy for damage detection with Lamb waves.

Memmolo et al. [110] used guided ultrasonic waves for detection and localization of hidden flaws in composite structures. A composite structure was designed for real scale components. They investigated different wave features and showed their changes in the presence of hidden failures.

Wavelet transform adopted by many researchers for damage quantification. Rucka [111] carried out damage identification on beam structure and used wavelet transform at high modes. His results were more accurate on high deflection shapes. Grabowska et al. [112] and Katunin et al. [113] worked on damage detection caused by delamination in composite using Wavelet transform with optimized parameters. Despite delamination being the most complex type of damage, their method and findings were very effective for industrial applications. Radzienski et al. [114] presented a new method for damage detection based on experimentally obtained modal parameter. Their method was applicable for measuring fatigue damage in the aluminum beam with frequency as baseline modal parameter.

Other experimental optical approaches such as Digital Image Correlation (DIC) and Thermography (Thermoelastic Stress Analysis (TSA) and Electronic Speckle Pattern Interferometry (ESPI) 
technology) measure high spatially defined 3D displacements on structure in a wide frequency range. Zanarini et al. [115] presented ESPI-based procedure for fatigue assessment of mechanical components. They enhanced the description of the flexible behavior of components in a wide frequency range by means of a robust numerical differentiation approach and a constitutive model. Odeshi et al. [116] investigated failure of different aluminum alloy under tempering. Microstructure examination was performed. They also presented the corresponding fracture surface of these alloys with strain values and changing shear bands. Similar research on aluminum alloy was carried out by Farahani et al. [117] with numerical simulation and its experimental validation from DIC for damage quantification.

Belytschko et al [118] presented an Element-free Galerkin (EFG) method for static and dynamic fracture problems. The method used moving least-square (MLS) interpolants and only required nodal data. Different analytical techniques for structural health monitoring were presented by many other researchers [119-122]. Considering the temperature, Farahani et al. [123] determined stress intensity factor of a compact tension specimen in a fatigue crack growth test from Thermoelastic Stress Analysis (TSA). They used advanced discretization techniques in processing the results.

The discussed non-contact techniques are very useful for monitoring complex structure. These techniques overcome constraints such as fixture requirement and probe attachment on a sturcture.

\section{Damage quantification under thermo-mechanical loadings}

Mechanical properties of metallic structure are more often dependent on their operating temperature. Properties like Young's modulus, Yield strength or Ultimate tensile strength can change easily with varying temperature. In case of fatigue, failure is initiated from birth of a small crack and lead to catastrophic failure. The rise in temperature can lead to increase the size of the plastic zone near the crack tip which can affect crack propagation. Size of the plastic zone near the crack tip depends not only on the level of repeated loads but also on the material properties. It is very difficult to repair fatigue damage immediately, however, estimation of fatigue crack growth can make the preventive maintenance much easier. Therefore, considering the fatigue failure is the most common failure in mechanical structure, it is very critical to investigate the effect of thermal loads.

There are many applications in which a structure undergoes combined dynamic and thermal loads such as aircraft wings, gas turbine blades, reciprocating pistons, etc. These components are more often exposed to extreme loads and raised significant challenges to ensure structural integrity. This significance propelled researchers in the past to investigate the potential of dynamic response parameters in damage quantification for structures working under thermo-mechanical loadings.

Cheng et al. [124], used a thermal-acoustic load for testing structures' dynamic response and sonic fatigue under coupled loads. They presented a numerical process for thermal acoustic test and used Monte-Carlo theory. The selected working temperature range was from $22^{\circ} \mathrm{C}$ to $400^{\circ} \mathrm{C}$. The damage was observed from frequency and temperature plot as shown in Figure 11. 

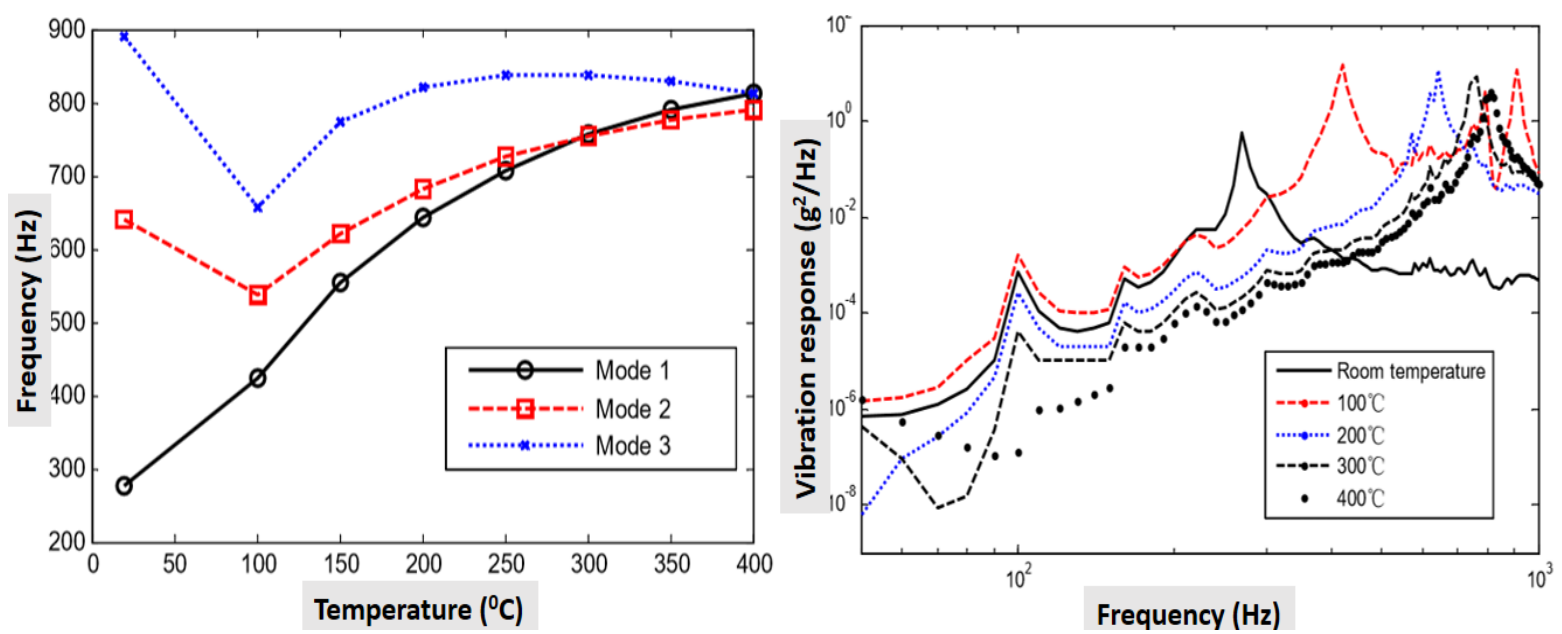

Figure 11: The change of the modal frequency and acceleration response.

Makhlouf and Jones [125] \& Lin et al. [126] investigated the crack growth behavior of ferritic stainless steel. They considered intermediate growth rates as a function of test temperature, thermal exposure, and frequency. They concluded that the crack growth rate increases with the increase in temperature. Higher than normal growth rates were observed at $475{ }^{\circ} \mathrm{C}$ and attributed to an embrittlement process which was known to occur in this temperature regime in high-chromium ferritic stainless steels.

Bachschmid et al [127] presented 3D non-linear finite element analyses on a cracked shaft. These analyses were aimed to introduce the effect of thermal stresses with static and dynamic loads. Opening and closing mechanism of crack affected by thermal loading were reported in terms of stress distribution. Kulak and Hughes [128] examined the effect of dimensional tolerances, frequency, and temperature on bearing stiffness. They found out that the stiffness of the structure greatly dependent on temperature, while barely influenced by geometric variations. The effects of environmental conditions on modal behavior of a lab specimen, I-girder, concrete box-girder, and steel plate girder bridges were also presented by Zolghadri et al. [129]. Vibration and temperature data were used to understand how the natural frequency of a bridge typically vary due to a change in temperature as shown in Figure 12.

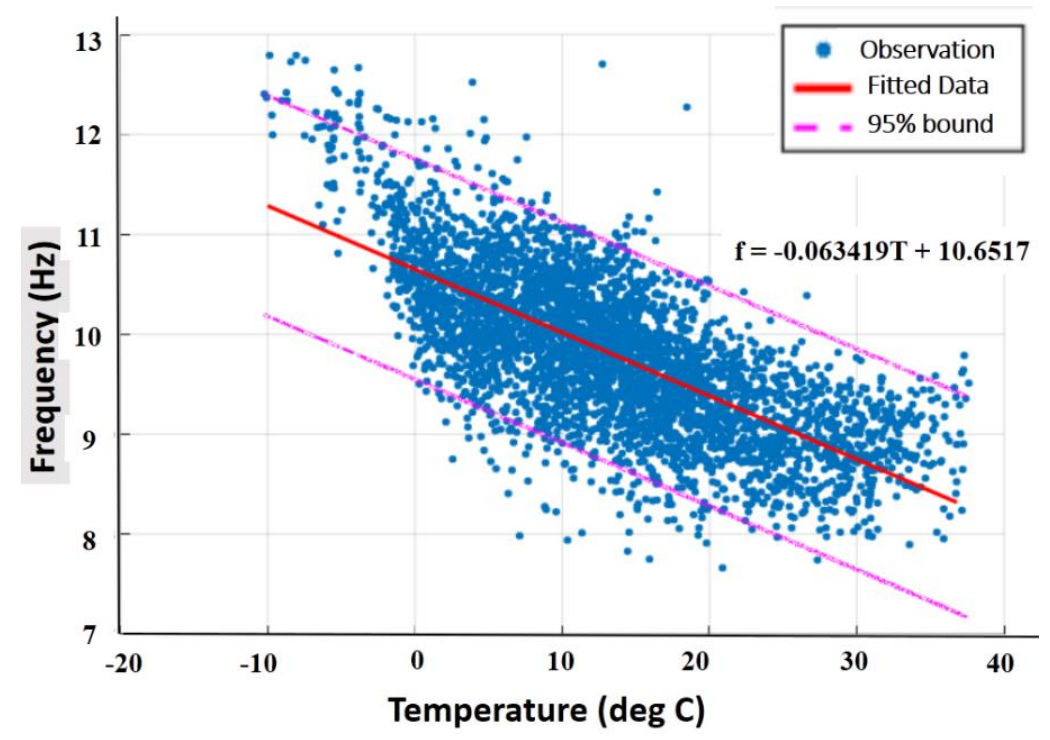

Figure 12: Relation of Natural Frequencies ( $3^{\text {rd }}$ mode) to Temperature of the Perry Bridge. 
$\mathrm{Lu}$ et al. [130] investigated the effect of thermal aging on fatigue crack growth (FCG). The crack surfaces and crack growth paths were analyzed as shown in Figure 13. Tsay et al. [131] performed experiments on low carbon steel specimens under repeated thermal shock loads. The effect of loads was found as a major contributor in the crack growth kinetics. Recently, relations between crack lengths, number of cycles and temperature were also reported [132-134]. These relations were extracted from the experimental data performed on aluminum alloys at different temperatures on various type of specimens as shown in Figure 14.
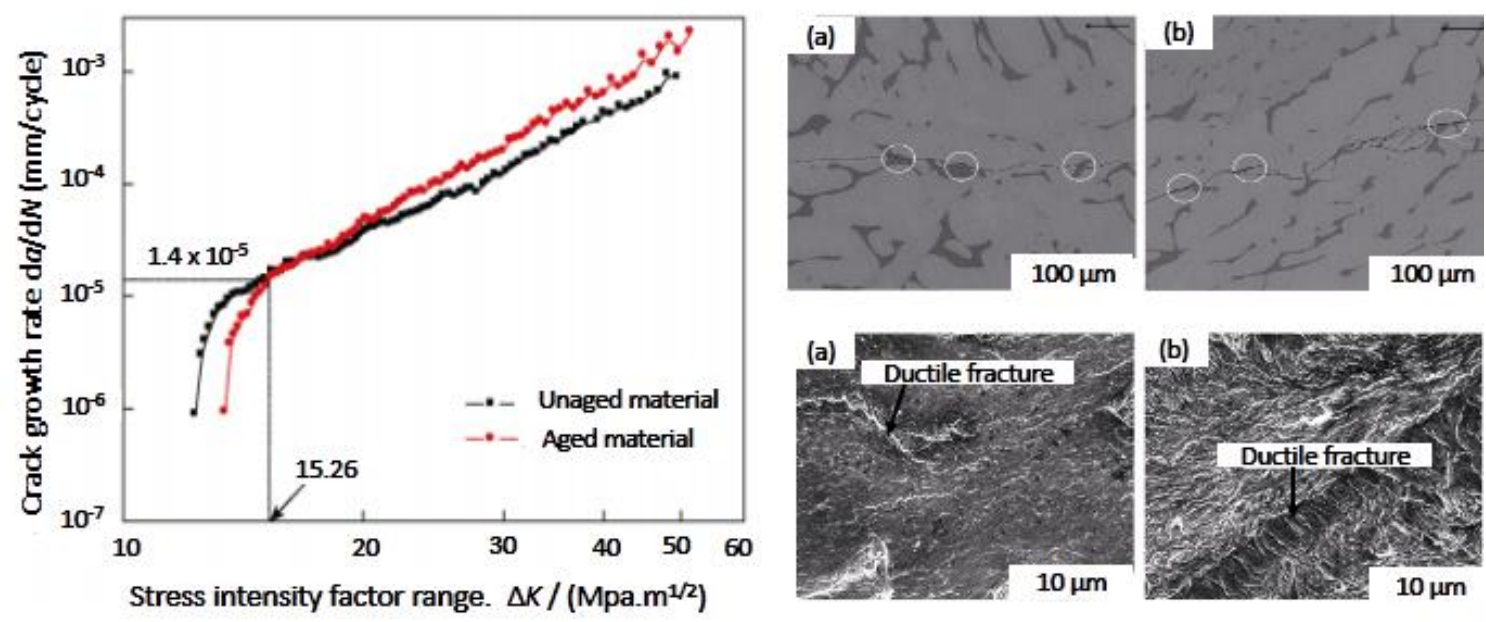

Figure 13: da/dN- $\Delta \mathrm{K}$ curves and crack pattern for the unaged and aged materials.

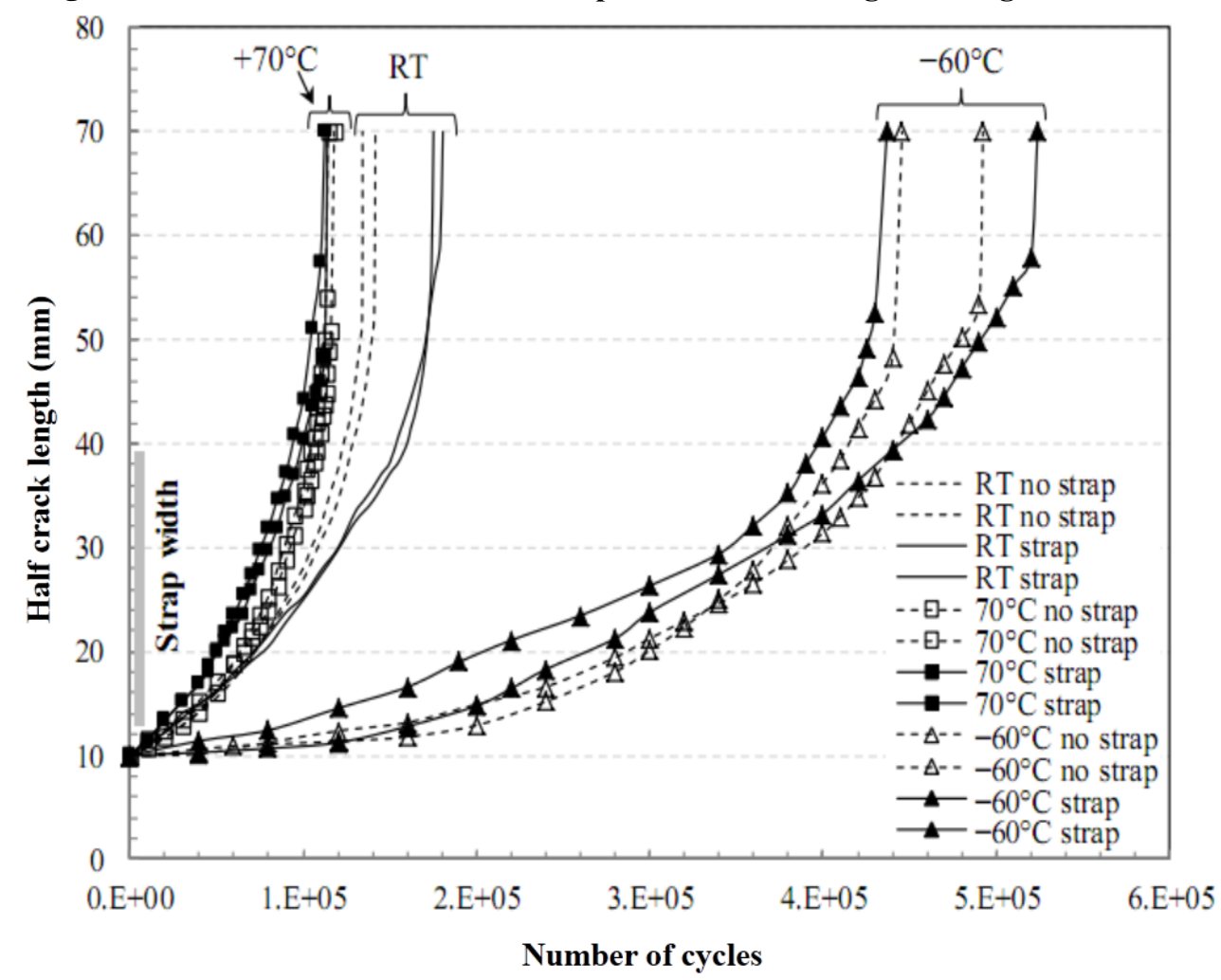

Figure 14: Crack length vs No. of load cycles for specimens with $\&$ without bonded crack retarders.

Ma et al. [135-136] proposed an analytical method (based on a transfer matrix) for modal analysis of a simply supported steel beam with multiple transverse open cracks under different temperatures. They modelled crack as a rotational spring and hence limited in quantification of damage. Same approach was 
used by many other researcher [137-141] and they used change of natural frequency as a key input in the damage identification.

An algorithm for structure health monitoring was presented by a few researchers [142-144]. They developed an integrated monitoring system for durability and assessment of bridges and turbine rotor at elevated temperatures. Their practice was mainly based on the response of different sensors and visual inspections using enhanced realistic deterioration models.

\section{Comparative study}

In the above review, several methods and techniques are presented. These can detect damage in metallic and non-metallic structures. A comparative study among different damage detection techniques is comprised in Table 1. In a low or free noise area, dynamic response measurements such as frequency, mode shape, and amplitude can effectively determine the damage and more likely its quantity and location. These methods need less complex data and operator training. However, the mode shape-based damage detection has a basic limitation of accurate sensor placement. Conversely, other technologies such as wave propagation and thermography are less affected by crack location but have to deal with complex data in their experimental pre-requisites.

Table 1: Comparative study among different damage detection techniques

\begin{tabular}{|c|c|c|c|c|c|c|c|}
\hline $\begin{array}{l}\text { Methodology } \\
\text { /Parameters }\end{array}$ & $\begin{array}{c}\text { Natural } \\
\text { Frequency } \\
\text { measurement }\end{array}$ & $\begin{array}{c}\text { Mode } \\
\text { shape and } \\
\text { parameters }\end{array}$ & $\begin{array}{c}\text { Amplitude } \\
\text { Response } \\
\text { measurement }\end{array}$ & $\begin{array}{c}\text { Elastic } \\
\text { wave } \\
\text { Propagation } \\
\text { approach } \\
\end{array}$ & $\begin{array}{c}\text { Guided } \\
\text { Ultrasonic } \\
\text { waves }\end{array}$ & $\begin{array}{l}\text { Wavelet } \\
\text { transform }\end{array}$ & $\begin{array}{l}\text { Thermography } \\
\text { methods }\end{array}$ \\
\hline $\begin{array}{l}\text { Effective } \\
\text { damage } \\
\text { detection }\end{array}$ & $\sqrt{ }$ & $\sqrt{ }$ & $\sqrt{ }$ & $\sqrt{ }$ & $\sqrt{ }$ & $\sqrt{ }$ & $\sqrt{ }$ \\
\hline $\begin{array}{c}\text { Distortion } \\
\text { due to Noise }\end{array}$ & $\sqrt{ }$ & $\sqrt{ }$ & $\sqrt{ }$ & & & $\sqrt{ }$ & \\
\hline $\begin{array}{c}\text { Complex } \\
\text { data }\end{array}$ & & & & $\sqrt{ }$ & $\sqrt{ }$ & $\sqrt{ }$ & \\
\hline $\begin{array}{c}\text { Distortion } \\
\text { due to } \\
\text { temperature }\end{array}$ & $\sqrt{ }$ & $\sqrt{ }$ & $\sqrt{ }$ & & & & $\sqrt{ }$ \\
\hline $\begin{array}{l}\text { Normalized } \\
\text { mode shape } \\
\text { requirement }\end{array}$ & & $\sqrt{ }$ & & & & $\sqrt{ }$ & \\
\hline $\begin{array}{c}\text { Accuracy } \\
\text { of sensor } \\
\text { placement }\end{array}$ & & $\sqrt{ }$ & & $\sqrt{ }$ & $\sqrt{ }$ & $\sqrt{ }$ & $\sqrt{ }$ \\
\hline $\begin{array}{c}\text { Effect } \\
\text { of damage } \\
\text { location }\end{array}$ & $\sqrt{ }$ & $\sqrt{ }$ & $\sqrt{ }$ & & $\sqrt{ }$ & & \\
\hline $\begin{array}{c}\text { Detection } \\
\text { of multiple } \\
\text { damage }\end{array}$ & & $\sqrt{ }$ & & $\sqrt{ }$ & $\sqrt{ }$ & $\sqrt{ }$ & $\sqrt{ }$ \\
\hline $\begin{array}{c}\text { Training } \\
\text { requirement }\end{array}$ & & & & $\sqrt{ }$ & $\sqrt{ }$ & $\sqrt{ }$ & $\sqrt{ }$ \\
\hline $\begin{array}{c}\text { Experimental } \\
\text { pre-requisite }\end{array}$ & & & & $\sqrt{ }$ & $\sqrt{ }$ & $\sqrt{ }$ & $\sqrt{ }$ \\
\hline
\end{tabular}




\section{Conclusion}

A comprehensive review is presented on the available methodologies of damage quantification with a focus on dynamic response measurements. Researchers have used amplitude and curvature of mode shape and have quantified the damage. These parameters are effective but very difficult to estimate in in-situ conditions on a structure. It requires a number of sensors to get the exact mode shape and the response remains limited to a few initial modes. Mode shape reflects the imaginary amplitude as the applied force and the damping values are not involved in the conventional calculations. The physical response can only be obtained if the structural damping and the excitation force are known. While damping depends largely on the material discontinuity in a structure.

Frequency and mode shape-based damage identification techniques have many limitations. Therefore, variation in the dynamic response in terms of amplitude with fewer limitations is more useful. Amplitude is the only response parameter which can give in-situ information regarding crack initiation and propagation under thermo-mechanical loads. A run time change in amplitude due to propagating crack can help in structural health monitoring and preventive maintenance.

The change in natural frequency can sometimes be insignificant for some specific size and location of a crack. It is observed that the frequency remains constant when the subsurface crack is initiated. However, even a small change in structure dynamics due to a crack will be captured by the probe in terms of amplitude response without dismantling the structure. Accuracy of results for damage identification is totally dependent on the input response parameter.

The effectiveness of different response parameters for a particular extend of damage still requires a comprehensive research. The variation in response parameters can also be compared for finding a most suitable parameter. This comparison on high modal order can be interested for identifying seeded and propagating cracks under thermomechanical loads.

Moreover, the response in terms of amplitude can be used for effective crack initiation and propagation analysis. However, still, efforts are required to develop a robust correlation between the crack behavior and the change in vibration amplitude of a structure. Damage quantification with dynamic response measurements still requires reliable analytical models, especially under thermomechanical or coupled loads. An analytical model that can provide a relationship in between the crack attributes and the dynamic response parameters, especially under the mentioned couple loads, can be a key contribution in the existing literature.

\section{References}

1. Doebling SW, Farrar CR, Prime MB, Shevitz DW (1996) Damage identification and health monitoring of structural and mechanical systems from changes in their vibration characteristics: a literature review. Los Alamos National Laboratory report.

2. Doebling SW, Farrar CR, Prime MB (1998) A summary review of vibration-based damage identification methods. Shock and Vibration 30: 91-105.

3. Fan W, Qiao P (2011) Vibration-based damage identification methods: a review and comparative study. Structure Health Monitoring 10(1): 83-111.

4. Das S, Saha P, Patro SK (2016) Vibration-based damage detection techniques used for health monitoring of structures: a review. Journal of Civil Structure Health Monitoring 6: 477-507.

5. Salawu OS (1997) Detection of structural damage through changes in frequency: a review. Engineering Structure 19(9): 718-723. 
6. Nandwana BP, Maiti SK (1997) Vibration based detection of location and size of edge crack in beam on multiple support. Proceedings of the 9th International Conference on Fracture: pp. 2603-2610.

7. Nandwana BP, Maiti SK (1997) Modeling of vibration of beam in presence of inclined edge or internal crack for its possible detection based on frequency measurement. Engineering Fracture Mechanics 58 (3): 193-205.

8. Khorshidi MK and Soltani D (2013) Diagnosis of type, location and size of cracks by using generalized differential quadrature and Rayleigh quotient methods. Journal of Theoretical and Applied Mechanics 43(1): 61-70.

9. Loya JA, Rubio L, Fernandez-Saez J (2006) Natural frequencies for bending vibrations of Timoshenko cracked beams. Continuum Mechanics and Structural Analysis 290(3-5): 1-14.

10. Ostachowicz WM and Krawczuk M (1991) Analysis of the effect of cracks on the natural frequencies of a cantilever beam. Journal of Sound \& Vibration 150(2): 191-201.

11. Batihan AC (2011) Vibration analysis of cracked beams on elastic foundation using Timoshenko beam theory. MS thesis, Middle East Technical University.

12. Yadav S, Roy SC, Mahto JN, Prasad RS (2014) Experimental investigation of crack in brass cantilever beam using natural frequency as basic criteria. International Journal of Scientific \& Engineering Research 5(9): 447-454.

13. Hu J and Liang R (1993) An integrated approach to detection of cracks using vibration characteristics. Journal of Franklin Institute 330(5): 841-853.

14. Kulkarni SS, Rajmane UC, Sawant PJ (2016) Crack detection in cantilever beam by frequency based method. International Journal of Advanced Research in Science, Engineering and Technology 3(1): 1174-1177.

15. Priyadarshini (2013) Identification of cracks in beams using vibrational analysis. MS thesis, National Institute of Technology.

16. Barad KH, Sharma DS, Vyas V (2013) Crack detection in cantilever beam by frequency based method. Procedia Engineering 51: 770 - 775.

17. Chang HY, Petroski HJ (1986) On detecting a crack by tapping a beam. International Journal of Pressure Vessels and Piping 22: 41-55.

18. S Chinchalkar (2001) Determination of crack location in beams using natural frequencies. Journal of Sound and Vibration 247(3): 417-429.

19. Lele SP, Maiti S. K (2002) Modeling of transverse vibration of short beams for crack detection and measurement of crack extension. Journal of Sound and Vibration 257(3): 559-583.

20. Liang RY, Choy FK, Hu J (1991) Detection of cracks in beam structures using measurements of natural frequencies. Journal of Franklin Institute 328(4): 505-518.

21. Narkis Y (1994) Identification of crack location in vibrating simply supported beam. Journal of Sound and Vibration 172 (4): 549-558.

22. Patil DP and Maiti SK (2003) Detection of multiple cracks using frequency measurements. Engineering Fracture Mechanics 70: 1553-1572.

23. Patil DP and Maiti SK (2005) Experimental verification of a method of detection of multiple cracks in beams based on frequency measurements. Journal of Sound and Vibration 281: 439-451.

24. EI Shifrin and R Ruotolo (1999) Natural frequencies of a beam with an arbitrary number of cracks. Journal of Sound and Vibration 222(3): 409-423.

25. Schlums DH and Dual J (1997) High resolution crack growth measurements in vibrating beams. Fatigue and Fracture of Engineering Materials and Structure 20(7): 1051-1058.

26. Jagdale PM and Chakrabarti MA (2013) Free vibration analysis of cracked beam. International Journal of Engineering Research and Applications 3(6): 1172-1176. 
27. Bhinge KV, Karajagi PG, Kulkarni SS (2014) Crack detection in cantilever beam by vibration techniques. International Journal of Engineering Research and Applications 3(4): 80-86.

28. Yamuna P, Sambasivarao K (2014) Vibration analysis of beam with varying crack location. International Journal of Engineering Research and General Science 2(6): 1008-1017.

29. Gounaris G, Dimarogonas A (1988) A finite element of a cracked prismatic beam for structural analysis. Computers \& Structures 28(3): 309-313.

30. Orhan S (2007) Analysis of free and forced vibration of a cracked cantilever beam. Non-Destructive Testing and Evaluation International 40: 443-450.

31. Thatoi DN, Nanda J, Das HC, Parhi DR (2012) Analysis of the dynamic response of a cracked beam structure. Applied Mechanics and Materials 187: 58-62.

32. Ratnam C, Rao GN, Murthy BSN, Rao VV (2015) Dynamic response of a multiple cracked cantilever beam. International Journal of Research in Engineering and Technology 4(12): 195-198.

33. Xu GY, Zhu WD, Emory BH (2007) Experimental and numerical investigation of structural damage detection using changes in natural frequencies. Journal of Vibration and Acoustics 129: 686-690.

34. Adams RD, Cawley P, Pye CJ, Stone BJ (1978) A vibration technique for non-destructively assessing the integrity of structures 20(2): 93-100.

35. Tsai TC, Wang YZ (1996) Vibration analysis and diagnosis of a cracked shaft. Journal of Sound and Vibration 192(3): 607-620.

36. Smith SW and McGowan PE (1989) Locating damaged members in a truss structure using modal test data: a demonstration experiment. 30th AIAA Structures, Structural Dynamics and Materials Conference. NASA Langley Research Center.

37. Cawley P and Adams RD (1979) The location of defects in structures from measurements of natural frequencies. Journal of Strain Analysis 14(2): 49-57.

38. Cawley P and Ray R (1988) A comparison of the natural frequency changes produced by cracks and slots. Journal of Vibration, Acoustics, Stress, and Reliability in Design 1988; 110: 366-370.

39. Ruotolo R and Surace C (1997) Damage assessment of multiple cracked beams: numerical results and experimental validation. Journal of Sound and Vibration 206(4): 567-588.

40. Sekhar AS (1999) Vibration characteristics of a cracked rotor with two open cracks. Journal of Sound and Vibration 223(4): 497-512.

41. Salawu O S (1997) Detection of structural damage through changes in frequency. Engineering Structures 19(9): 718-723.

42. Chondros TG, Dimarogonas AD, Yao J (1998) A continuous cracked beam vibration theory. Journal of Sound and Vibration 215(1): 17-34.

43. Christides S, Barr ADS (1984) One-dimensional theory of cracked Bernoulli-Euler beams. International Journal of Mechanical Science 26 (11-12): 639-648.

44. Dentsoras AJ and Dimarogonas AD (1983) Resonance controlled fatigue crack propagation in a beam under longitudinal vibrations. International Journal of Fracture 23: 15-22.

45. Gudmundson P (1982) Eigen frequency changes of structures due to cracks, notches or other geometrical changes. Journal of Mechanics and Physics of Solids 30(5): 339-353.

46. Gudmundson P (1983) The dynamic behavior of slender structures with cross-sectional cracks. Journal of Mechanics and Physics of Solids 31(4): 329-345.

47. Kam TY and Lee TY. Detection of cracks in structures using modal test data. Engineering Fracture Mechanics 42(2): 381-387.

48. Khiem NT and TV Lien (2001) A simplified method for natural frequency analysis of a multiple cracked beam. Journal of Sound and Vibration 245(4): 737-751. 
49. Krawczuk M and Ostachowicz WM (1993) Transverse natural vibrations of a cracked beam loaded with a constant axial force. Journal of Vibration and Acoustics 115: 524-528.

50. Liang RY, Hu J, Cho F (1992) Quantitative NDE technique for assessing damages in beam structures. Journal of Engineering Mechanics 118(7): 1468-1487.

51. QS Li (2001) Vibratory characteristics of multi-step beams with an arbitrary number of cracks and concentrated masses. Applied coustics 62: 691-706.

52. Naik SS and Maiti SK (2007) Special issues related to detection of circumferential crack at different orientations in pipes by vibration method. 14th International Congress on Sound and Vibration, Cairns, Australia.

53. Revi R and Indu VS (2015) Crack detection of propped cantilever beam using dynamic analysis. International Journal of Technical Research \& Applications 3(4): 274-278.

54. Salawu S and Williams C (1994) Damage location using vibration mode shapes. Proceedings of the 12th International Modal Analysis Conference, Bethel: pp. 933-939.

55. Batabyal AK (2007) Crack detection in cantilever beam using vibration response. 8th International Conference on Vibration Problems: pp. 27-32.

56. Rizos PF and Aspragathos N (1990) Identification of crack location and magnitude in a cantilever beam from the vibration modes. Journal of Sound and Vibration 138(3): 381-38.

57. Agarwalla DK and Parhi DR (2013) Effect of crack on modal parameters of a cantilever beam subjected to vibration. Procedia Engineering 51: 665-669.

58. Shinde YD and Katekar SD (2014) Vibration analysis of cantilever beam with single crack using experimental method. International Journal of Engineering Research \& Technology 3(5): 16441648.

59. Chati M, Rand R, Mukherjee S (1997) Modal analysis of a cracked beam. Journal of Sound and Vibration 207(2): 249-270.

60. Pandey AK, Biswas M, Samman MM (1991) Damage detection from changes in curvature mode shapes. Journal of Sound and Vibration 145(2): 321-332.

61. Simoen E, Roeck GD, Lombaert G (2015) Dealing with uncertainty in model updating for damage assessment: A review. Journal of Mechanical Systems and Signal Processing 56-57: 123-149.

62. Haisty BS and Springer WT (1988) A general beam element for use in damage assessment of complex structures. Journal of Vibration, Acoustics, Stress, and Reliability in Design 110: 389394.

63. Bouboulas AS, Georgantzinos SK, Anifantis NK (2012) Vibration analysis of cracked beams using the finite element method. Advances in Vibration Engineering and Structural Dynamics Chapter 8: pp. 181-204.

64. Bisi PS (2011) Vibration and buckling analysis of cracked composite beam. MS thesis, National Institute of Technology.

65. Mohammed OD (2015) Dynamic Modelling and Vibration Analysis for Gear Tooth Crack Detection. PhD thesis, Lulea University of technology.

66. Gounaris GD, Papadopoulos CA, Dimarogonas AD (1996) Crack identification in beams by coupled response measurements. Computers \& Structures 58(2): 299-305.

67. Nikolakopoulos PG, Katsareas DE, Papadopoulos CA (1997) Crack identification in frame structures. Computers \& Structures 64(1-4): 389-406.

68. Chen LW and Chen CL (1988) Vibration and stability of cracked thick rotating blades. Computers \& Structure 28(1): 67-74.

69. Dirr BO and Schmalhorst BK (1988) Crack depth analysis of a rotating shaft by vibration measurement. Journal of Vibration, Acoustics, Stress, and Reliability in Design 110: 158-164. 
70. Shen MHH and Pierre C (1990) Natural modes of Bernoulli-Euler beams with symmetric cracks. Journal of Sound and Vibration 138(1): 115-134.

71. Xiaoqing Z, Qiang H, Feng L (2010) Analytical approach for detection of multiple cracks in a beam. Journal of Engineering Mechanics 136: 345-357.

72. Heydari M, Ebrahimi A, Behzad M (2014) Forced vibration analysis of a Timoshenko cracked beam using a continuous model for the crack. Engineering Science and Technology 17: 194-204.

73. Swamidas ASJ, Yang X, Seshadri R (2004) Identification of cracking in beam structures using Timoshenko and Euler formulations. Journal of Engineering Mechanics 130: 1297-1308.

74. Qian GL, Gu SN, Jiang JS (1990) The dynamic behavior and crack detection of a beam with a crack. Journal of Sound and Vibration 138(2): 233-243.

75. Papadopoulos CA and Dimarogonas AD (1987) Coupled longitudinal and bending vibrations of a rotating shaft with an open crack. Journal of Sound and Vibration 117(1): 81-93.

76. Papadopoulos CA and Dimarogonas AD (1992) Coupled vibration of cracked shafts. Journal of Vibration and Acoustics 114: 461-467.

77. Papadopoulos CA and Dimarogonas AD (1988) Stability of cracked rotors in the coupled vibration mode. Journal of Vibration, Acoustics, Stress, and Reliability in Design 110: 356-359.

78. Yuen MMF (1985) A numerical study of the Eigen parameters of a damaged cantilever. Journal of Sound and Vibration 103(3): 301-310.

79. Boltezar M, Strancar B, Kuhelj A (1998) Identification of transverse crack location in flexural vibrations of free-free beams. Journal of Sound and Vibration 211(5): 729-734.

80. Jena PK, Thatoi DN, Nanda J, Parhi DRK (2012) Effect of damage parameters on vibration signatures of a cantilever beam. International Conference on Modelling, Optimization and Computing 38: pp. 3318 - 3330.

81. Gasch R (1993) A survey of dynamic behaviour of a simple rotating shaft with transverse crack. Journal of Sound and Vibration 160(2): 313-321.

82. Mayes IW and Davies WGR (1984) Analysis of the response of a multi-rotor-bearing system containing a transverse crack in a rotor. Journal of Vibration, Acoustics, Stress and Reliability in Design 106: 139-145.

83. Aghdam NJ, Hassanifard S, Ettefagh MM, Nanvayesavojblaghi A (2014) Investigating fatigue life effects on the vibration properties in friction stir spot welding using experimental and finite element modal analysis. Journal of Mechanical Engineering 60(11): 735-741.

84. Shang DG and Barkey ME (2005) Analysis of fatigue crack behaviour based on dynamic response simulations and experiments for tensile-shear spot-welded joints. Fatigue and Fracture of Engineering and Materials 29(1): 23-30.

85. Wang G and Barkey ME (2005) Fatigue crack identification in tensile-shear spot welded joints by dynamic response characteristics. Journal of Engineering Materials and Technology 127: 310-317.

86. Wang $G$ and Barkey ME (2004) Fatigue cracking and its influence on dynamic response characteristics of spot welded specimens. Society for Experimental Mechanics 44(5): 512-521.

87. Wang G, Barkey ME (2006) Investigating the spot weld fatigue crack growth process using x-ray imaging. Welding Research: 84-90.

88. He J, Lu Z, Liu Y (2012) New method for concurrent dynamic analysis and fatigue damage prognosis of bridges. Journal of Bridge Engineering 17(3): 396-408.

89. Oskouei AV and Dumanoglu AA (1997) Influence of crack on the dynamic response of concrete gravity dam. Teknik Dergi 8(3): 1457-1470. 
90. Nwosu DI, Swamidas AS, Guigne JY, Olowokere DO (1995) Studies on influence of cracks on the dynamic response of tubular t-joints for nondestructive evaluation. Proceedings of SPIE: 11221129.

91. Rao VN and Eischen JW (2016) Failure analysis of mixed mode crack growth in heavy duty truck frame rail. Case Studies in Engineering Failure Analysis 5-6: 67-74.

92. Dompierre B, Wyart E, Mesbah, Thirifay M F (2013) Fatigue crack growth analysis on a rotor blade under forced response. Proceedings of ASME Turbo Expo, Texas: 1-9.

93. Muhlstein CL, Howe RT, Ritchie RO (2004) Fatigue of polycrystalline silicon for microelectromechanical system applications: crack growth and stability under resonant loading conditions. Mechanics of Materials (36): 13-33.

94. Rahmatalla S and Schallhorn C (2014) Diagnosis of retrofit fatigue crack re-initiation and growth in steel-girder bridges for proactive repair and emergency planning. A Cooperative Research Project. US Department of Transportation.

95. Sadek M, Bergstrom J, Hallback N, Burman C (2016) Computation of and testing crack growth at $20 \mathrm{kHz}$ load frequency. Procedia Structural Integrity 2: 1164-1172.

96. Wang J, Seah SKW, Wong EH, Cadge D (2008) Fracture mechanics study of fatigue crack growth in solder joints under drop impact. 58th Electronic Components and Technology Conference, Florida: pp. 1601-1605.

97. Sarrafi A, Mao Z, Niezrecki C, Poozesh P (2018) Vibration-based damage detection in wind turbine blades using phase- based motion estimation and motion magnification. Journal of Sound and vibration 421: 300-318.

98. Tcherniak D (2016) Rotor anisotropy as a blade damage indicator for wind turbine structural health monitoring systems. Mechanical Systems and Signal Processing 74: 183-198.

99. Sinou J, Faverjon B (2012) The vibration signature of chordal cracks in a rotor system including uncertainties. Journal of Sound and Vibration 331:138-154.

100. Hoell S, O Piotr (2015) Structural damage detection in wind turbine blades based on time series representations of dynamic responses. Conference on Smart Materials and Nondestructive Evaluation for Energy Systems. Canada.

101. Jiang Z, Karimirad M, Moan T (2014) Dynamic response analysis of wind turbines under blade pitch system fault, grid loss, and shutdown events. Wind Energy 17(9): 1385-1409.

102. Karimirad M, Michailides C (2018) Fault condition effects on the dynamic response of Vshaped offshore wind turbine. Journal of marine sciences and technology: 1-12.

103. Rahman A, Ismail Z, Noroozi, Chao O (2012) Study of open crack in rotor shaft using changes in frequency response function phase. International journal of damage mechanics. 22(6): 791-807.

104. Adams D, White J, Rumsey M, Farrar C (2011) Structural health monitoring of wind turbines: method and application to a HAWT. Wind Energy 14(4): 603-623.

105. Krawczuka M., Palacza M, Ostachowicz W (2004) Wave propagation in plate structures for crack detection. Finite elements in analysis and design 40: 991-1004.

106. Zak A, Radzienski M, Krawczuk M, Ostachowicz W (2012) Damage detection strategies based on propagation of guided elastic waves. Smart Material Structure 21: 18.

107. Kudela P, Zak A, Krawczuka M, Ostachowicz W (2007) Modelling of wave propagation in composite plates using the time domain spectral element method. Journal of Sound and vibration 302: 728-745.

108. Kumar D. S, Mahapatra D. R, Gopalakrishnan S (2004) A spectral finite element for wave propagation and structural diagnostic analysis of composite beam with transverse crack. Finite Elements in Analysis and Design 40;1729-1751. 
109. Lee B C and Staszewski W J (2007) Lamb wave propagation modelling for damage detection: I. Two-dimensional analysis. Smart Material Structure 16: 249-259.

110. Memmolo V, Boffa N, Maio L, Monaco E, Ricci F (2018) Damage Localization in Composite Structures Using a Guided Waves Based Multi-Parameter Approach. Aerospace 5(4):111.

111. Rucka M (2011) Damage detection in beams using wavelet transform on higher vibration modes. Journal of theoretical and applied mechanics 49(2): 399-417.

112. Grabowskaa J, Palacz M, Krawczuk M (2008) Damage identification by wavelet analysis. Mechanical Systems and Signal Processing 22: 1623-1635.

113. Katunin A (2014) Detection and localization of delamination in composite beams using fractional B-spline wavelets with optimized parameters. Maintenance and reliability 16(3): 391399.

114. Radzienski M, Krawczuk M, Palacz M (2011) Improvement of damage detection methods based on experimental modal parameters. Mechanical Systems and Signal Processing 25: 2169-2190.

115. Zanarini A (2008) ESPI measurements in structural dynamics: fatigue life assessment. Dantec Dynamics International Conference and User Meeting Sep. 22-23, Germany, pp. 1-20.

116. Odeshi A G, Adesola A O, Badmos A Y (2013) Failure of AA 6061 and 2099 aluminum alloys under dynamic shock loading. Engineering Failure Analysis 35: 302-314.

117. Farahani B V, Amaral, Belinha J, Tavares P J, Moreira P (2017) A GTN Failure Analysis of an AA6061-T6 Bi-Failure Specimen Procedia Structure Integration: 981-988.

118. Belytschko T, Lu Y, Gu L, Tabbara M (1995) Element-free Galerkin methods for static and dynamic fracture. International Journal of Solids Structure 32 (17-18): 2547-2570.

119. Sinou J (2009) A review of damage detection and health monitoring of mechanical systems from changes in the measurement of linear and non-linear vibrations. Mechanical Vibrations: Measurement, Effects and Control: 643-702.

120. Zhao X (2015) New methods for structural health monitoring and damage localization, $\mathrm{PhD}$ thesis, University of Sheffield, UK.

121. Zhou Y, Figueiredo E, MaiaN, Perera R (2015) Damage detection and quantification using transmissibility coherence analysis. Shock and Vibration http://dx.doi.org/10.1155/2015/290714

122. Li J (2011) Analytical fatigue damage calculation for wind turbine support structure, MS thesis, Western reserve university.

123. Farahani V, Tavares P J, Moreira P, Belinha J (2017) Stress intensity factor calculation through thermoelastic stress analysis finite element and RPIM meshless method. Engineering Fracture Mechanics 183: 66-78.

124. Cheng H, Li HB, Zhang W, Wu ZQ, Liu BR (2016) Dynamic response analysis of an aircraft structure under thermal-acoustic loads. Journal of Physics 744: 1-8.

125. Makhlouf K and Jones JW (1993) Effects of temperature and frequency on fatigue crack growth in $18 \% \mathrm{Cr}$ ferritic stainless steel. International Journal of Fatigue 15(3): 163-171.

126. Lin CH, Sheu JW, Lee DM (1999) Local thermal effect on the growth rate of fatigue crack. International offshore and polar engineering conference, Brest: pp. 195-200.

127. Bachschmid N, Pennacchi P, Tanzi E (2006) Analysis of the thermal effects in rotor shaft affected by transverse crack. Research Activities on High Performance Computing Clusters at CILEA: 11-25.

128. Kulak RF and Hughes TH (1994) Identification of factors that influence the stiffness of highdamping elastomer seismic isolation bearings. Reactor Engineering Division, Argonne National Laboratory, Argonne, Illinois. 
129. Zolghadri N, Halling MW, Barr PJ, Foust N (2015) Effects of Temperature on Bridge Dynamic Properties. Final Report, US Department of Transportation and Research.

130. Lu X, Li S, Zhang H, Wang Y, Wang X (2015) Effect of thermal aging on the fatigue crack growth behavior of cast duplex stainless steels. International Journal of Minerals, Metallurgy and Materials 22(11): 1163-1170.

131. Tsay LW, Young MC, Chou FY, Shiue RK (2004) The effect of residual thermal stresses on the fatigue crack growth of laser-annealed 304 stainless steels. Materials Chemistry and Physics 88: 348-352.

132. Price JWH, Chang M, Kerezsi B (2004) Cracking of carbon steel components due to repeated thermal shock. SIF2004 Structural Integrity.

133. Syed AK, Zhang X, Moffatt JE, Fitzpatrick ME (2017) Effect of temperature and thermal cycling on fatigue crack growth in aluminum reinforced with GLARE bonded crack retarders. International Journal of Fatigue 98: 53-61.

134. Khan MA, Khan SZ, Sohail W, Khan H, Sohaib M, Nisar S (2015) Mechanical fatigue in aluminum at elevated temperature and remaining life prediction based on natural frequency evolution. Fatigue and Fracture of Engineering Materials and Structure 38(8): 897-903.

135. Ma Y, Chen G, Yang F (2017) Modal Analysis of a Simply Supported Steel Beam with Cracks under Temperature Load. Shock and Vibration.

136. Ma Y and Chen G (2017) Modal analysis of a rectangular variable cross-section beam with multiple cracks under different temperatures. Journal of Vibroengineering 18(5): 2717-3424.

137. Mahi A, Bedia EA, Tounsi A, Mechab I (2010) An analytical method for temperature-dependent free vibration analysis of functionally graded beams with general boundary conditions. Composite Structures 92: 1977-1887.

138. Wang Z , Liu B , Han Y (2012) Free vibration frequency variation analysis of a cracked aluminum alloy beam under high temperatures. Journal of Harbin Engineering University 33(3): 320-324.

139. Gupta A, Jain NK, Salhotra R (2017) Effect of thermal environment on vibration analysis of isotropic micro plate with inclined crack based on modified couple stress theory. 24th International Congress on Sound and Vibration.

140. Joshi PV, Jain NK, Ramtekkar GD, Virdia GS (2016) Vibration and buckling analysis of partially cracked thin orthotropic rectangular plates in thermal environment. Thin-Walled Structures 109: 143-158.

141. Zhao X, Hu QJ, Crossley W, Du CC, Li YH (2017) Analytical solutions for the coupled thermoelastic vibrations of the cracked Euler-Bernoulli beams by means of Green's functions. International Journal of Mechanical Sciences.

142. Comisu C, Taranu N, Boaca G, Scutaru M (2017) Structural health monitoring system of bridges. Procedia Engineering 199: 2054-2059.

143. Shul'zhenko NG, Zaitsev BF, Asaenok AV, Protasova TV (2017) Deformation and vibrationinduced stress intensity of a high-temperature turbine rotor with a breathing transverse crack. Strength of Materials 49(6): 751-759.

144. O'Hara PJ and Hollkamp J (2016) Modeling fatigue crack propagation in a Ti-alloy at elevated temperature within a reduced-order model framework. Structures, Structural Dynamics, and Materials Conference California, USA. 
The role of dynamic response parameters in damage prediction

\author{
Zai, Behzad Ahmed
}

Sage

Zai B, Khan MA, Khan KA, et al., (2019) The role of dynamic response parameters in damage prediction. Proceedings of the Institution of Mechanical Engineers, Part C: Journal of Mechanical Engineering Science, Volume 233, Issue 13, July 2019, pp. 4620-4636 https://doi.org/10.1177/0954406219841083

Downloaded from Cranfield Library Services E-Repository 